\title{
An Innovative Extinction Angle Control Technique for Soft Starting the Three Phase Squirrel Cage Induction Motor
}

\begin{abstract}
Mohamed Faizal ${ }^{\dagger}$ and Subburaj*
Abstract - The time old conventional starting schemes though have been in use for many years exhibit some drawbacks and such drawbacks can be overcome only with power electronic motor starters. The advent of modern power electronic devices and the control systems supported by modern digital processing units have led to the development of digital power electronic soft starting schemes that guaranteed higher degrees of compliance of the requirements of an ideal soft starter for the induction motor. This research paper presents the results of the comparative study of the two versions of soft starting schemes viz the phase angle control and extinction angle control and brings about the highlights, by way of MATLAB / SIMULINK based simulation and experimental verification, and the advantages of the extinction angle control.
\end{abstract}

Keywords: Extinction angle control, Total harmonic distortion, Power factor, Power semiconductor devices, Soft switching, MOSFETs.

\section{Introduction}

Three phase induction motor, the work horse of the electrically powered industry, of different capacities are being traditionally started using different starting arrangements depending upon the size and application of the motor. Direct on line starting, Star Delta starting and the Auto transformer starting are some of the starting schemes applied to the induction motor [1].

The main objectives of a starter for the induction motor are as follows.

1. To provide a convenient means for connecting and disconnecting the $\mathrm{AC}$ three phase power of appropriate rating with the motor with minimal arcs and sparks. The DOL starter or the oil immersed DOL starter well serves this purpose

2. To reduce the starting current drawn by the motor, because if the full rated voltage is applied to the motor as in the case of the DOL starter in a single step the starting current of the motor will be as high as seven times the rated full load current [2].

Considering such circumstances, the starter is meant to supply reduced voltage at starting and limit the starting current within the allowable boundaries during the starting process. Typically the star delta starter reduces the applied voltage at starting to $1 / \sqrt{ }(3)$ times the rated voltage and thus can reduce the starting current. As compared to the star

$\dagger$ Corresponding Author: Dept. of Electrical and Electronics Engineering, National College of Engineering, Maruthakulam, Tirunelveli, Tamil Nadu, India. (aamdfaizal@yahoo.com)

* Dept. of Electrical and Electronics Engineering, National Engineering College, K.R. Nagar, Kovilpatti, Tamil Nadu, India. (subbuneceee@yahoo.com)

Received: October 2, 2014; Accepted: February 16, 2016 delta starter the auto transformer starter is more efficient in the sense that the output voltage of the auto transformer starter can be continuously changed from the zero voltage level to the rated voltage level.

In this case the starting current can be limited to safe levels throughout the starting process. The auto transformer starter can be activated both manually and it can be realised as a motorised starting scheme with the help of a servo motor.

3. To protect the motor under over load conditions - and this feature of a starter is out of scope of this research paper. Some of the disadvantages of the conventional starters are

a. They are costly because of the use of copper in the holding coils and silver or gold plating in the contacts.

b. They are bulky.

c. They need special maintenance procedures.

Apart from these basic disadvantages the conventional starters are not flexible. For example, with the solid state starters, a control action like decreasing or increasing the applied voltage to the motor under control can be implemented in a fraction of a second accurately which is not possible with the traditional starters. As compared to the conventional starters the modern solid state starters are realised using SCR, MOSFET or IGBT offer more flexible controllability especially when designed to operate with the modern digital signal processing systems [3].

The core rational difference between the voltage reduction schemes, during the starting process, in the conventional starters and the solid state starters is that the conventional starters use amplitude control that happens along the $\mathrm{Y}$ axis and that the solid state controllers used in modern soft 


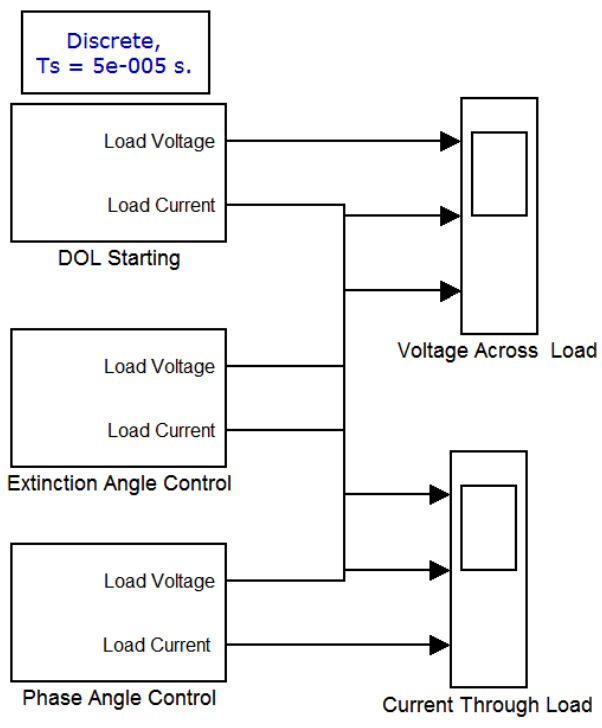

Fig. 1. Three schemes of soft starting - DOL, extinction angle and phase angle control.

starting schemes use time axis control where the RMS value of the output voltage is controlled by controlling the duration of conduction in every cycle [4].

The phase angle control is a typical time axis control method in which the duration of conduction is varied from 0 to 180 degrees in the positive half cycle and 180 to 360 degrees in the negative half cycle. The switches are turned on after angle $\alpha$ from the 0 degree for positive half cycle and after angle $\alpha$ after the 180 degrees in the negative half cycle and conduction continues until the following zero crossings at 180 degrees and 360 degrees respectively for positive and negative half cycles. Fig.1 shows the three starting schemes DOL, extinction angle and phase angle control.

In contrary to the phase angle control, in the case of extinction angle control the conduction starts exactly at the 0 degree instant and the 180 degree instant for the positive and negative half cycles and continues until or before the consequent zero crossings at 180 and 360 degrees respectively. The output voltage is controlled by varying the extinction angle.

Phase angle control is the pioneer because it was the SCR that was used to achieve it. Since it is difficult to turn off the SCR, while it is conducting, the extinction angle control scheme came into existence after the advent of MOSFETS and IGBTs [5]. MOSFETs and IGBTs can be turned on and off easily at the required instants by applying the turn on signals and removing them whenever necessary.

The two control schemes as applied to the AC voltage controller can be extended as soft starters for induction motors and a comparative study of the performance of these schemes is all that is covered in this research paper.

After this introduction part under section-1 methodology of proposed techniques are given in section-2. The MATLAB/SIMULINK based simulation model is presented in section-3. A discussion of results is presented in section4 and experimental verification setup in section-5, followed by the conclusion in section- 6 .

\section{Methodology}

An induction motor can basically be compared to a transformer with the stator winding of the IM related to the primary winding of a transformer and the rotor conductors of the IM related to the secondary winding of the transformer. A motor at stand still is like a transformer with its secondary short circuited, exhibiting the lowest impedance looking from the primary side of the transformer and as the motor starts up and picks up speed the short circuit of the motor is released gradually and the impedance grows gradually until the motor reaches the full speed when it offers the highest impedance. This is the reason why a motor at start up draws heavy current which slowly falls down as the motor picks up speed towards the rated speed. It is to be noted that the speed of the motor has to be increased from $0 \mathrm{rpm}$ to the rated speed, say $1440 \mathrm{rpm}$, as a continuous process. As the motor is accelerated from stand still towards $1440 \mathrm{rpm}$ its speed should have travelled along all the possible values in a continuous scale of speed from $0 \mathrm{rpm}$ until it reaches the rated $1440 \mathrm{rpm}$.

The philosophy of soft starting is that right from the starting instant until the rated speed is reached the voltage is gradually increased in such a manner that at no instant the current drawn by the motor is more than a specific limit for that instant.

Soft starting is a technique that allows the motor to undergo the transient from the state of $0 \mathrm{rpm}$ towards the final rated speed with minimal deviations from the line of dynamic equilibrium by way of administering the just required quantity of energy from time to time in a continuous manner.

The three phase AC voltage regulator is a suitable candidate for soft starting the three phase induction motor. By continuously changing the switching angle thereby controlling the conduction period continuously the voltage applied to the motor can be gradually increased in a manner with respect to time such that only the just required power is imparted to the motor during the starting process as the speed picks up from $0 \mathrm{rpm}$.

The three phase AC voltage regulator can be controlled in a different number of ways. The phase angle control, the extinction angle control, the symmetrical angle control, alternate phase and extinction angle control and the multiple switched symmetrical angle control are some of the popular techniques. Of these different techniques the phase angle control and the extinction angle control scheme are studied in detail, as the main focus of this research and the findings in simulation as well as experimental verification have been consolidated. Parameters like stator 
current, THD of stator current, Power factor during starting, torque pulsations during starting and the rate of rise of speed were all compared for both the methods of soft starting.

There are two types of soft starting systems. In one method known as the open loop method none of the output parameters like current, or torque or speed is monitored [6]. The voltage applied to the motor is just increased in a smooth time bound manner with a fixed slope. The second method is the closed loop method in which any one of the parameters like stator current, or torque or speed of the motor are continuous monitored and compared against set values and the increments of voltages will be carried out accordingly. It is the open loop soft starting method that is discussed in this paper and that the two schemes implemented using solid state power electronic circuits namely the phase angle control scheme and the extinction angle control scheme are compared.

$$
T=\frac{k S V_{1}^{2} R_{2}}{R_{2}^{2}+S^{2} X_{20}^{2}}
$$

where,

$$
\begin{aligned}
& V_{1}=\text { supply voltage } \\
& S=\text { slip } \\
& R_{2}=\text { rotor circuit resistance } \\
& X_{20}=\text { rotor reactance at standstill }
\end{aligned}
$$

From the fundamental torque equation of the induction motor as shown in Eq. (1) it is evident that the torque produced is proportional to the square of the applied voltage $\left(\mathrm{T}_{1} \alpha \mathrm{V}_{1}^{2}\right)$. And if the motor is applied with full rated voltage then the motor is accelerated suddenly and the sudden acceleration may cause mechanical stresses in the parts of the motor as well as the associated mechanical linkages [7, 8]. Huge starting currents may heat up the motor and also because of sudden increase in currents the feeder voltages may dip affecting other voltage sensitive loads connected to the same feeder [9].

Soft starting is a means of starting the motor with reduced acceleration such that the motor speed rises up slowly while the current drawn by the motor is also limited [10]. Though soft starting reduces the acceleration and prolongs the period of starting the electro mechanical stress on the entire system is well within limits and this leads to a long reliable life of the entire system [11].

The torque produced by the motor can be controlled by controlling the current or by controlling the applied voltage as shown in the relation given in Eq. (2).

$$
T_{2}=T_{1}\left(i_{2} / i_{1}\right)^{2}=k^{*} T_{1}\left(V_{2} / V_{1}\right)^{2}
$$

With reference to the equation the torque all along the starting process can be reduced and kept within limits by applying voltage in small incremental quantities [12, 13].

\section{Simulation Model of Phase Angle Control and Extinction Angle Control Schemes}

The performances of the two starting schemes namely the phase angle control and extinction angle control are compared against the DOL method of starting.

In the Direct on Line starting scheme the full voltage is applied to the motor in a single instance like a step input. During the studies the motor was left in the no load condition. The following parameters were recorded.
a. Starting Current.
b. Speed
c. Torque
d. THD and
e. Power factor.

The MATLAB /SIMULINK model for DOL scheme is shown in Fig. 2.

Table 1. Motor Specifications

\begin{tabular}{c|c}
\hline Voltage & $440 \mathrm{~V} \mathrm{3} \mathrm{Phase}$ \\
\hline Frequency & $50 \mathrm{~Hz}$ \\
\hline Type & Squirrel Cage Induction Motor \\
\hline Power & $5.4 \mathrm{HP}(4 \mathrm{~kW})$ \\
\hline
\end{tabular}

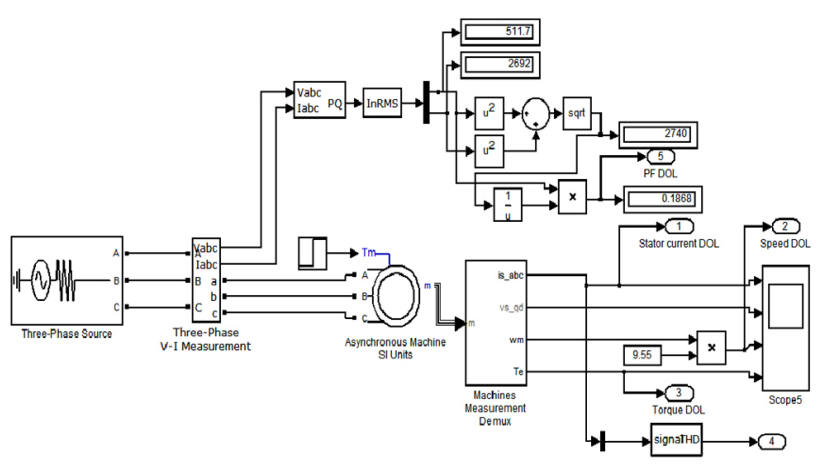

Fig. 2. The MATLAB/SIMULINK Model for DOL starting of three phase Induction Motor.

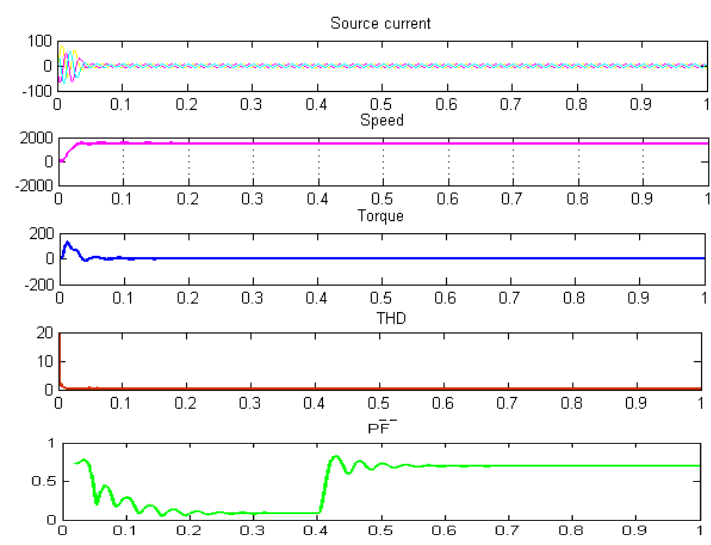

Fig. 3. Source Current, Speed, Torque, THD and PF with DOL starting. 
With reference to Fig. 3 in the case of DOL starting scheme the starting current is as high as 100A. The motor gets started with an enormous acceleration such that it may definitely reduce the life of motor windings and also the mechanical accessories associated with the motor. The Power Factor is fairly high for a moment and it falls to lower values as the motor starts up. It can be considered that the DOL scheme offers good power factor at starting. Since no power electronic systems are involved the power quality is high and there are no issues associated with THD of source current etc. However because of the sudden rise in the motor current the terminal voltage of the main feeding source may fall by a degree depending upon 'strength' of the feeder and this is definitely an issue attempted to be addressed by the soft starting schemes.

\subsection{Phase angle control scheme}

Fig. 4 shows the arrangement of the phase angle control scheme. In between the AC source and the three phase induction motor is a set of three $\mathrm{AC}$ voltage controllers. These AC voltage controllers in each phase have one main MOSFET in series with the induction motor feeding phase, controlling power and one MOSFET for freewheeling.

\subsection{Switching pulse generation}

In the phase angle control scheme for every half cycle of

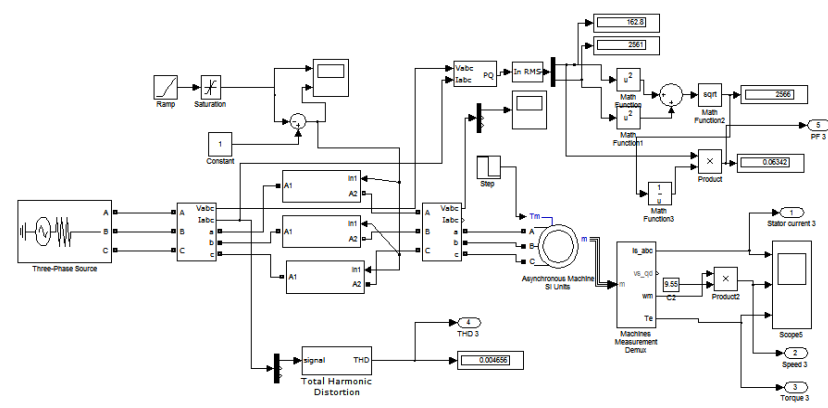

Fig. 4. The scheme for phase angle control.

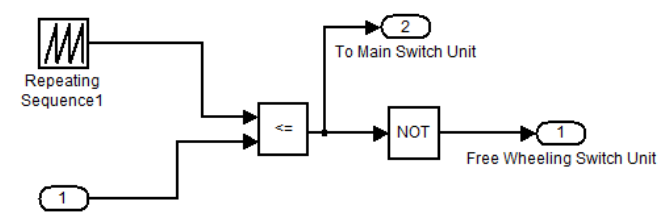

Fig. 5. The pulse creation unit for phase angle control.

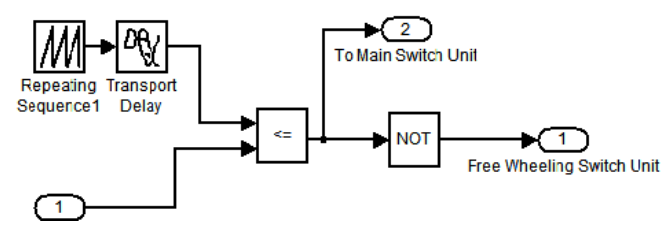

Fig. 6. The scheme for producing phase shifted switching pulses for the B phase (Transport delay for time equivalent to 120 degrees) the AC source a switching pulse is to be generated. Thus a train of switching pulses with increasing order of pulse widths will be generated synchronously.

The MATLB SIMULINK sub system for producing the switching pulses is as shown in Fig. 5 and Fig. 6. A repeating periodic ramp of time period $10 \mathrm{~ms}$ is created. This ramp is constantly compared against a slowly rising DC signal. This DC signal rises from 0 towards 1 with any desired rise time and will stay at 1 as long as the motor is running. If the rise time of this signal is long then the starting period or the duration of the starting process of the motor will be elongated.

In a three phase system, similar to the $\mathrm{R}$ phase, the $\mathrm{Y}$ and the $\mathrm{B}$ phase switching signals are generated in a similar manner except that next to the repeating sequence is a time delay correspondingly for 120 degrees and 240 degrees respectively for the $\mathrm{Y}$ and the $\mathrm{B}$ phases.

The waveforms pertaining to the repeating sequence, the time varying reference DC and the output of the comparator are shown in the Fig. 7. The waveforms of the load side voltage per phase and the corresponding current in case of a resistive load are shown in Fig. 8.

The parameters such as starting current, speed, torque, THD and power factor for phase angle control scheme are shown in Fig. 9.

\subsection{Extinction angle control}

The model of the extinction angle control (Fig. 10) is

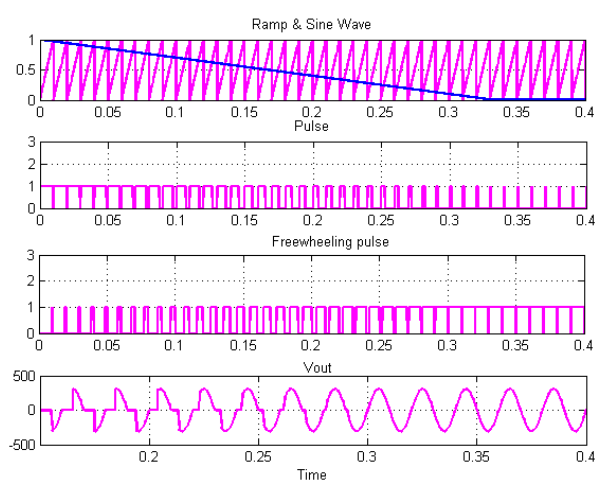

Fig. 7. Methodology for producing the phase angle control

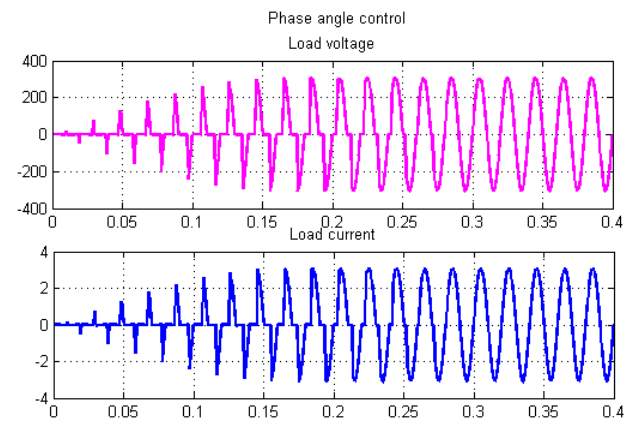

Fig. 8. Load side voltage and current waveform - Phase angle control with a resistive load. 


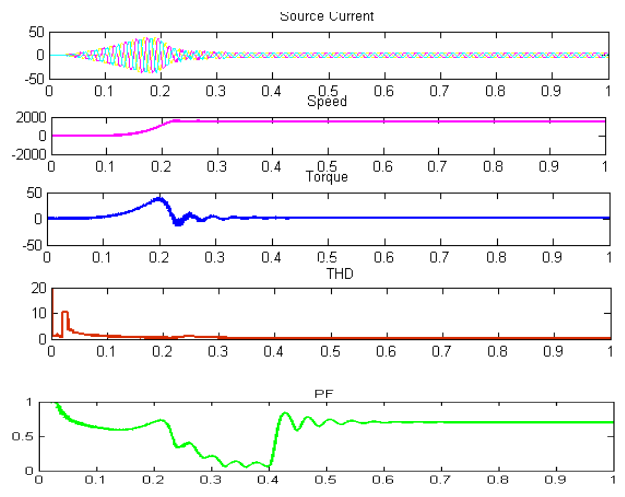

Fig. 9. Source current, Acceleration, Torque, THD and PF - Phase angle control type of soft starting of three phase induction motor.

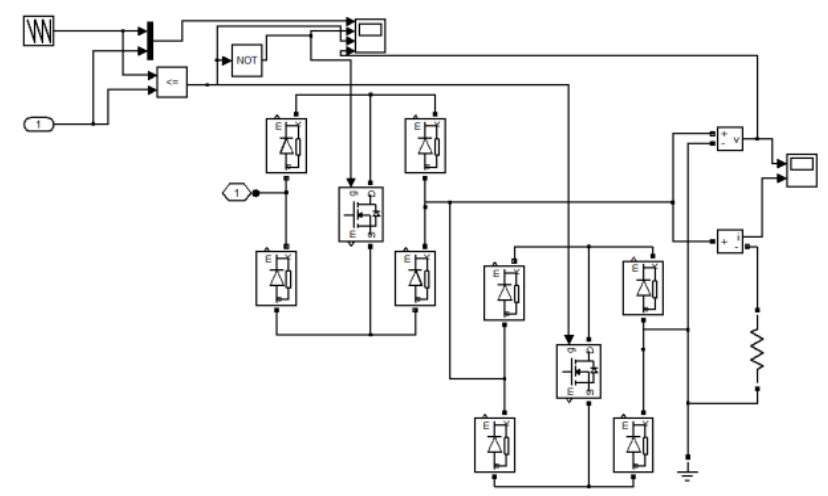

Fig. 10. The MATLAB / SIMULINK model of the Power circuit topology is for Extinction angle control.

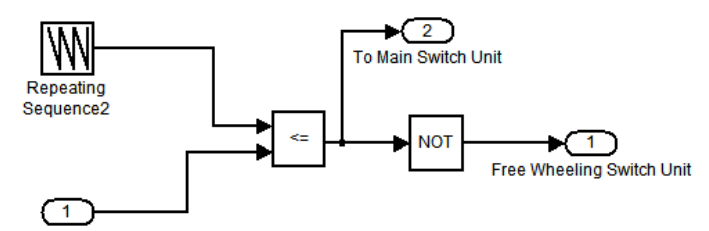

Fig. 11. Scheme for producing the switching pulses Extinction angle control (The repeating sequence makes the difference)

same as phase angle control scheme. Everything remaining the same the only difference between the phase angle control and the extinction angle control schemes as shown in Fig. 12 is that the shape of the repeating sequence is different in both the cases. A repeating sequence with right handed slope is used for the phase angle control while a repeating sequence of left handed slope is used for the extinction angle control. The switching pulse generation sub system for the extinction angle control scheme and the associated waveforms are as shown in Fig. 11 and Fig. 12.

For an easy comparison of the phase angle control and the extinction angle control the waveforms of the output voltage across the load in one phase is shown in Fig. 13 for a duration of the starting period. The different parameters such as current, speed, torque, THD and power factor for

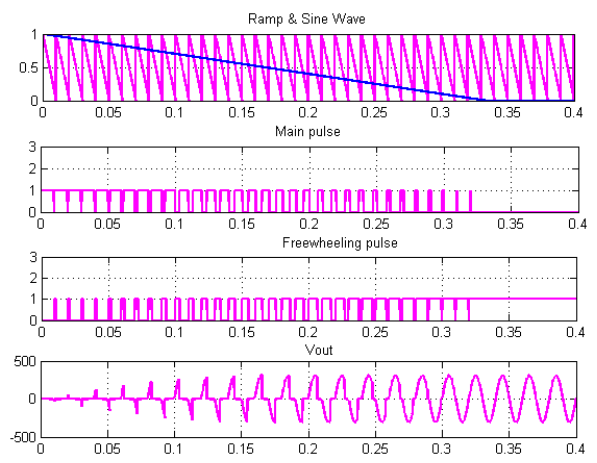

Fig. 12. Methodology of creating the switching pulses for Extinction angle control and the wave form of the output voltage.
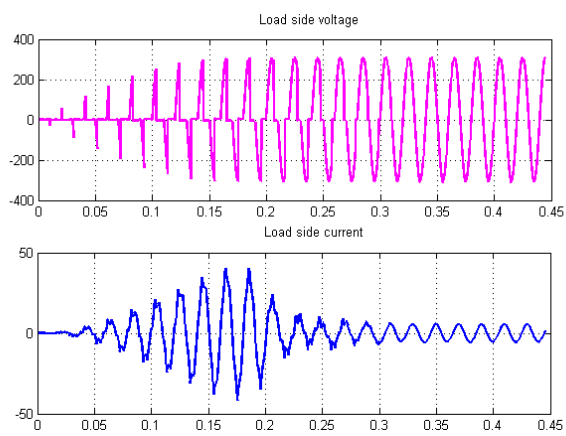

Fig. 13. Voltage output across the load and current through the load - Extinction Angle Control.
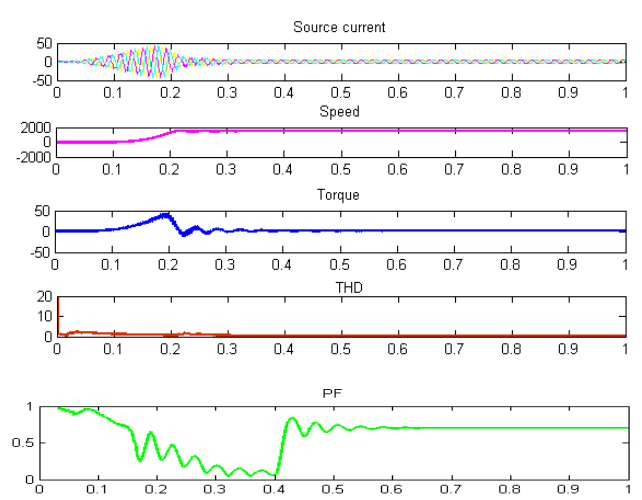

Fig. 14. Stator current, Speed, Torque, THD and PF extinction angle control.

extinction angle control are clearly shown in Fig. 14.

\section{Results and Discussions}

A comparison of all the vital parameters has been carried out among the three schemes of starting. A convenient MATLAB / SIMULINK model was adopted to easily compare the performance of the three schemes of starting.

\subsection{Starting current}

With reference to Fig. 15, comparisons of the starting 

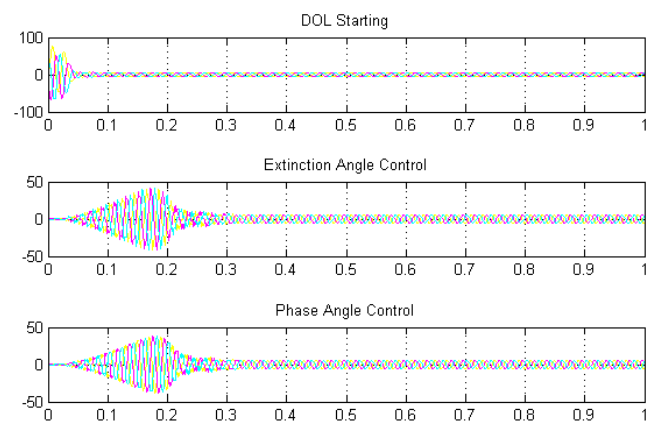

Fig. 15. Starting currents of the DOL, Extinction angle and Phase angle control.

currents have been carried out. It is clear that the DOL scheme of starting draws heavier starting current as high as 100 amps which is about 7 times the full load current of the 5.4HP induction motor. In the case of the phase angle controlled soft starting scheme the starting current is limited to 50 amps.

In the case of the extinction angle method of soft starting the starting current has been limited much below 50 amps and has not exceeded 50 amps. Thus it is evident that the soft starting method using the extinction angle scheme offers much smoother starting characteristics.

As for the soft starting schemes one of the main objectives is to reduce the starting current to lie below certain safe levels depending upon the specific motor and application.

While this can be achieved using the ac voltage controllers it is to be achieved only at the cost of some disadvantages. The first drawback of soft starting is that by either of the two schemes demonstrated here the starting acceleration is poor and the motor takes a longer time interval to reach the rated speed. Besides the use of switched control scheme affects the source current waveform as compared to any of the traditional starting schemes and the THD of the ac voltage controller based soft starting scheme is high. However, since only the minimal quantity of power is being delivered to the motor in a continuously increasing manner the soft starting schemes offer higher electrical energy efficiencies and good power factor while starting.

\subsection{Rate of rise of speed}

A comparison of the acceleration of the motor in the three methods of starting is given in Fig. 16. The DOL starting scheme exhibits a huge acceleration and as a result the motor reaches the rated speed at the earliest. Both the Phase angle control scheme and the extinction angle control scheme exhibit the same degree of reduced acceleration and both are suitable for smooth starting.

In the case of both extinction angle control and phase angle control the motor reaches the rated speed almost at the same time. Reduced acceleration reduces electro mechanical stresses in the motor and the associated
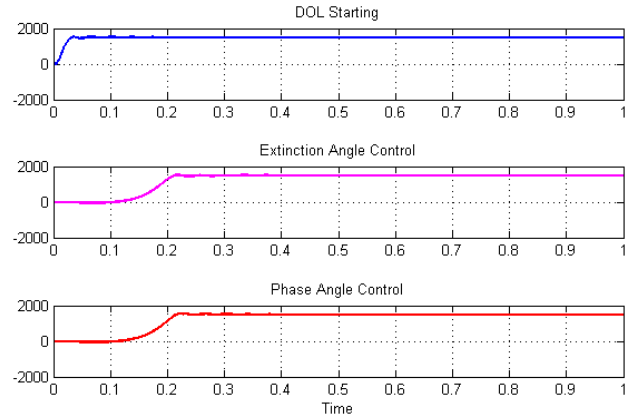

Fig. 16. Comparison of acceleration of the three systems of starting.
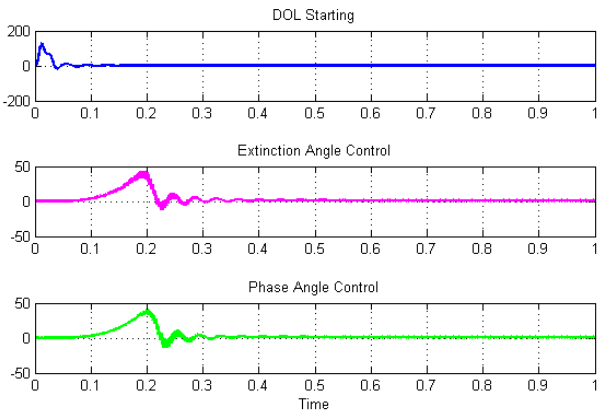

Fig. 17. Comparison of the torques produced by the three schemes of starting.

mechanical systems and increases the life of both the motor and the associated physical systems.

\subsection{Torque}

Fig. 17 shows a comparison of the torques produced by the three schemes of starting. The maximum torque is produced by the DOL schemes and it is as high as $125 \mathrm{NM}$ and this torque is produced by the DOL starting scheme at a very early stage of starting.

In the case of extinction angle control and the phase angle control the acceleration is gradual and the motor takes a longer period to reach the rated speed. Both the soft starting schemes offer the same starting pattern. Because of the switched nature of the source voltage there is much ripple in the torques produced by both the cases. The maximum torque is as high as $40 \mathrm{NM}$ This torque is less than the maximum producible torque of a typical motor under full load condition. Interestingly, the DOL starting scheme produces a torque much more than the full load torque and the soft starting schemes produce torques less than the full load torques even as the motor has been started in all the three cases under no load conditions.

\subsection{Total harmonic distortion}

Total Harmonic distortion is the measure of power quality of the stator current. The THD of one of the three phases of the stator currents have been monitored and plotted (Fig. 18). The DOL starter does not exhibit power 

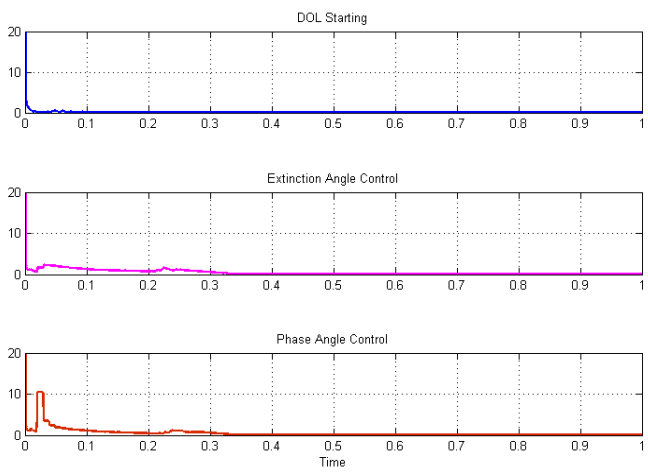

Fig. 18. THD
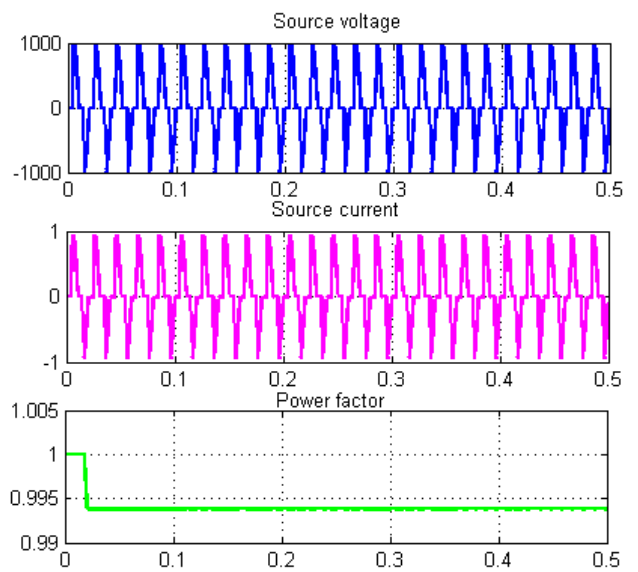

(a)
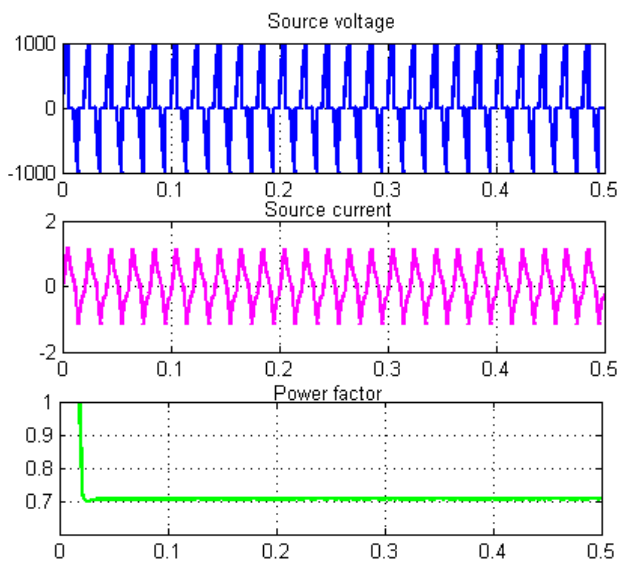

(b)

Fig. 19. Power factor improvement with RL load for (a). Extinction angle control and (b). Phase angle control.

quality issues since it does not have any discretely switching systems. The phase angle control scheme exhibits significantly large THD as compared to the extinction angle controller.

\subsection{Power factor}

With reference to the Fig. 19 and Fig. 20 the DOL starter

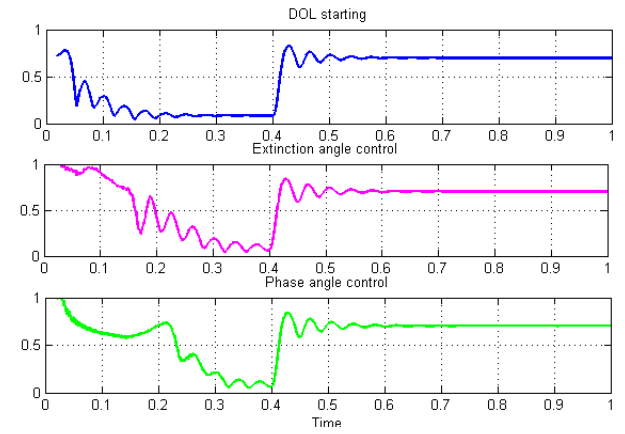

Fig. 20. Power factor: Comparison of power factor of the DOL, Extinction angle and phase angle schemes of starting.

scheme of starting shows up high power factor for a moment and then it comes down in a bumping fashion. The extinction angle provides leading power factor as shown in Fig. 19(a). This is one of the major advantages of using extinction angle control scheme. Also it offers good power factor as high as unity while the phase angle control scheme offers a maximum power factor of 0.7 (shown in Fig. 19(b)).

Compared to the phase angle control scheme the extinction angle scheme offers better power quality in regard to the source current with less THD, quicker reaching of the rated speed, high power factor and less ripple in torque.

\section{Experimental Verification Setup}

An experimental setup was constructed to validate the proposed idea of using the extinction angle control for the soft starting of three phase induction motor.

The specifications of the motor are as follows:

Type : Three Phase induction motor.

Voltage : :380V, $50 \mathrm{~Hz}$

Power : 3750 watts

Speed : 1440 RPM

Connection : Star

A set of two controllers were built one for the phase angle controller and the other for the extinction angle controller.

IRF 840 MOSFETS were used in the extinction angle controllers. For each phase two MOSFETS were used. These two MOSFETS were arranged inside a diode bridge unit so that the same MOSFET can be used for conduction during both half cycles. The two MOSFETS were respecttively used as the main MOSFET and the freewheeling MOSFET.

A Micro controller of type 89C51 was used as the control element. Zero crossing detectors were common for both the phase angle control system and the extinction angle control system.

For the phase angle control system the switches used 
were of type BY 139 Triacs. Triacs being bidirectional and that they can be used in association with the zero crossing to enable natural commutation were specifically used for the phase angle control scheme.

For both the phase angle control scheme and the extinction angle control scheme both sudden and soft starting arrangements were included and selected using push buttons connected to a particular port of the controlling Micro controller.

Optical isolation was used to isolate between the control section and the power section. In the case of the phase angle controller Opto Diac ICs were used and for the extinction angle control scheme opto coupler ICs MCT 2E were used.

The basic principle for the phase angle control and the extinction angle control is that a synchronous ramp is generated and a continuously raising DC output from a DAC was compared with the ramp. The resulting square pulses were used to trigger the Triac switches. The square pulses after due inversion was supplied to the extinction angle control power switches. While phase angle could happen in the Triac based three phase topology the extinction angle control was simultaneously carried out at the MOSFET based extinction angle control. However for implementing soft starting on the motor, the motor was connected to the phase angle control first and after observations it was then connected to the extinction angle control unit.

The experimental setup of the soft starting system is shown in Fig. 21. The various waveforms observed for extinction angle control scheme are presented in Figs. 22-30.

While the extinction angle control is in action the

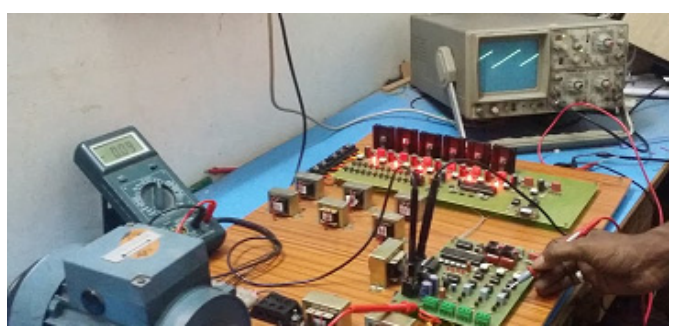

Fig. 21. Experimental hardware setup

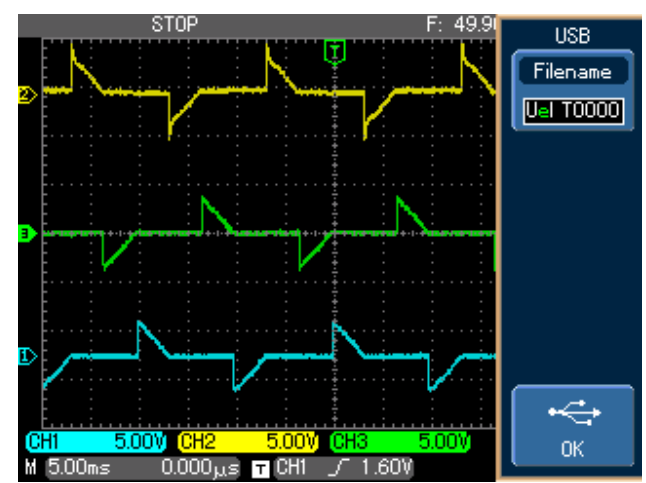

Fig. 22. Voltage across the switches for 90 degree conduction applied phase voltage initially drops in full across the three switches relevant for each phase. As the starting process goes on the duration of voltage drop across the switch falls and that across the load rises. Figs. 22 and 23 shows the voltage across the switches for nearly 90 degrees conduction and more than 90 degrees conduction respectively.

Even though the conduction of current happens through the switch for both positive half cycles, because of the bridge type arrangement using four diodes over the MOSFET the current through the MOSFET is uni directional through every positive and negative half cycles. This is shown in Fig. 24. The voltage across the $\mathrm{Y}$ phase winding for a conduction angle less than 90 degrees is shown in Fig. 25.

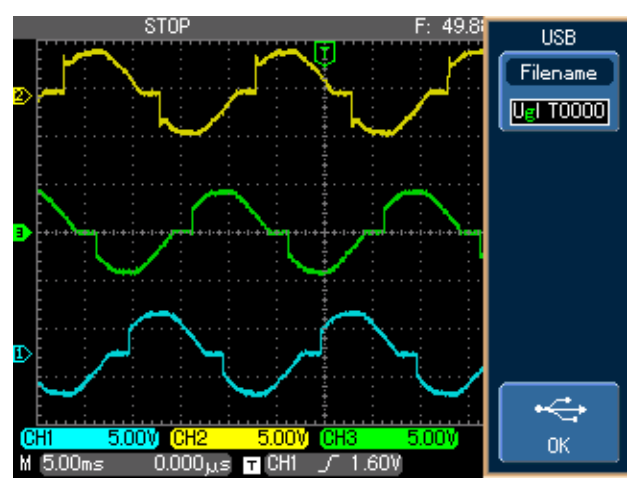

Fig. 23. Voltage across the switches for less than 90 degree conduction

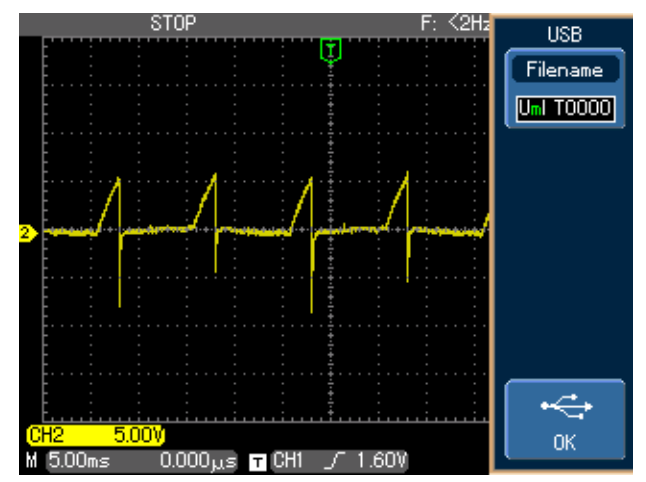

Fig. 24. Current through the switch in R phase

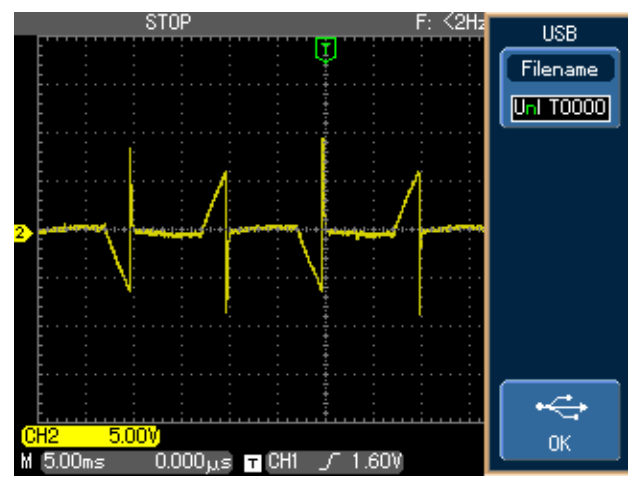

Fig. 25. Voltage across the $\mathrm{Y}$ phase winding at a conduction angle less than 90 degrees. 


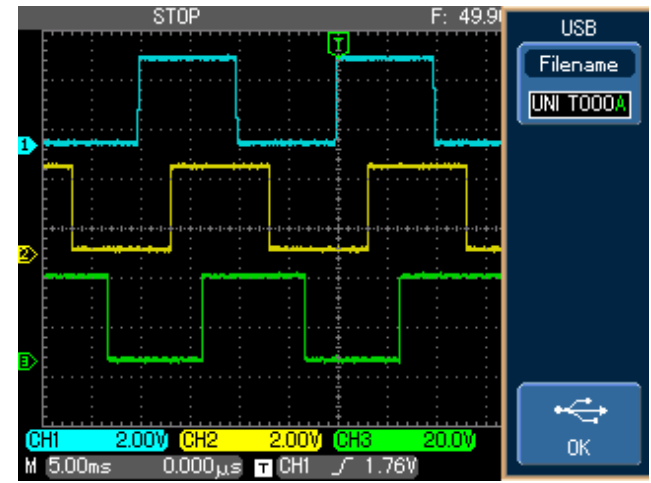

Fig. 26. Three phase zero crossing signals

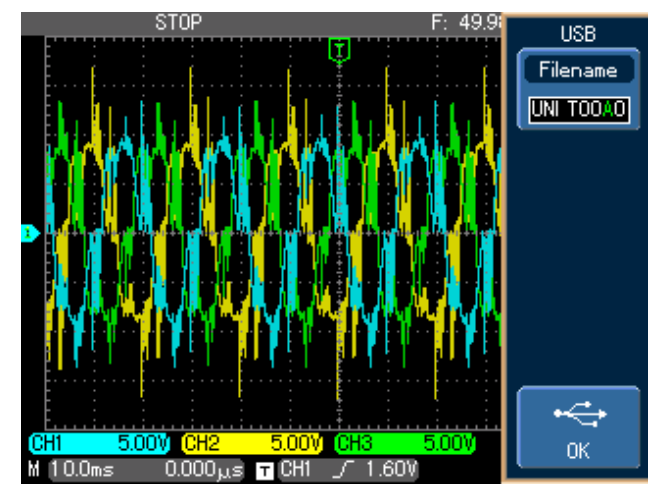

Fig. 27. Stator current at near steady state for extinction angle control.
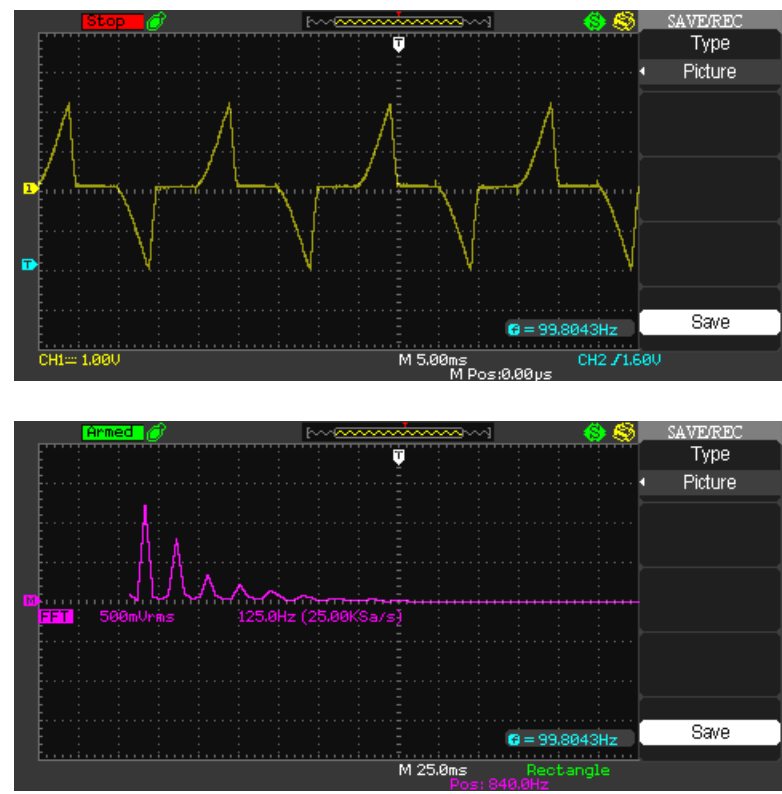

Fig. 28. Typical waveform of the extinction angle control$90^{\circ}$ conduction (Voltage across one phase winding and FFT)

The zero crossing of each of the three phases are to be obtained for the synchronous control of the soft starting scheme. The delays in application of the switching pulses
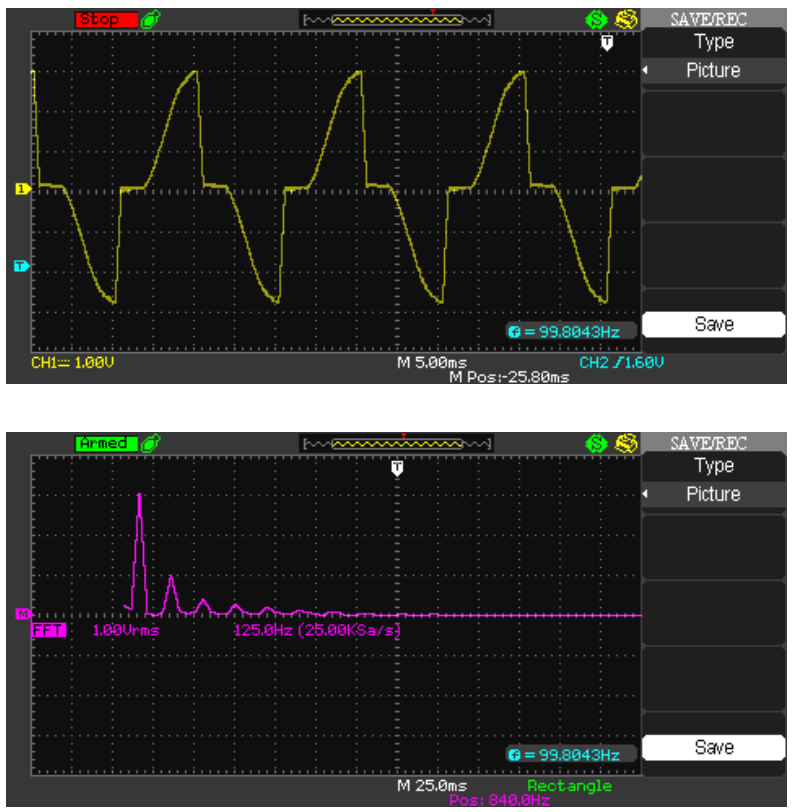

Fig. 29. Typical waveform of the extinction angle controlgreater than $90^{\circ}$ conduction (Voltage across one phase winding and FFT)

are calculated with reference to the zero crossing instants. Fig. 26 shows the zero crossing signal as observed from the zero crossing detectors. These signals are applied to the micro controllers where the delays will be maintained with reference to these three zero crossing signals.

After the starting transient period the motor eventually gets the full voltage with the MOSFET switching all entering into full period conduction mode. Fig. 27 shows up the voltage across the motor windings just as the motor picks up full speed and with the full voltages applied across all the three phase windings.

The drawback of the time axis control, in either case, viz the phase angle control or the extinction angle control is that the harmonic performance of the schemes are poor as compared to the DOL starting scheme. Simulations reveal that the harmonic performance during the soft starting transient period is better in case of the extinction angle control than the phase angle control. Since the authors do not have the facility to record the dynamically changing harmonic performance in the case of time axis controlled systems a recording of the harmonic spectrum for different conduction angles in the case of extinction angle scheme have been recorded and presented in Figs. 28, 29 and 30. The relevance of these images is that as the conduction angles increase the relative harmonic magnitudes decrease which suggests that with extinction angle control as the conduction angle increases slowly the harmonic performance improves accordingly. As for the Harmonic study, using the observations by discretely setting different conduction angles the average THD has been estimated to be presented in Table 2 . 
Table 2. Comparison of simulated and experimental parameters

\begin{tabular}{c|c|c|c|c|c|c}
\hline & \multicolumn{2}{|c|}{ DOL starting scheme } & \multicolumn{2}{c|}{ Phase angle control scheme } & \multicolumn{2}{c}{ Extinction angle control scheme } \\
\hline & $\begin{array}{c}\text { Simulated } \\
\text { results }\end{array}$ & $\begin{array}{c}\text { Experimental } \\
\text { results }\end{array}$ & $\begin{array}{c}\text { Simulated } \\
\text { results }\end{array}$ & $\begin{array}{c}\text { Experimental } \\
\text { results }\end{array}$ & $\begin{array}{c}\text { Simulated } \\
\text { results }\end{array}$ & $\begin{array}{c}\text { Experimental } \\
\text { results }\end{array}$ \\
\hline Time taken to reach steady state & $0.05 \mathrm{~s}$ & $0.1 \mathrm{~s}$ & $0.2 \mathrm{~s}$ & $0.25 \mathrm{~s}$ & $0.2 \mathrm{~s}$ & $0.25 \mathrm{~s}$ \\
\hline Starting current & $60 \mathrm{~A}$ & $73 \mathrm{~A}$ & $41 \mathrm{~A}$ & $45 \mathrm{~A}$ & $36 \mathrm{~A}$ & $41 \mathrm{~A}$ \\
\hline Average THD during starting & 0.004599 & 0.00782 & 0.03086 & 0.0582 & 0.02066 & 0.0384 \\
\hline Average power factor during starting & 0.78 & 0.72 & 0.735 & 0.713 & 0.789 & 0.784 \\
\hline Maximum torque during starting & $127 \mathrm{Nm}$ & $134 \mathrm{Nm}$ & $42 \mathrm{Nm}$ & $45 \mathrm{Nm}$ & $38 \mathrm{Nm}$ & $41 \mathrm{Nm}$ \\
\hline
\end{tabular}
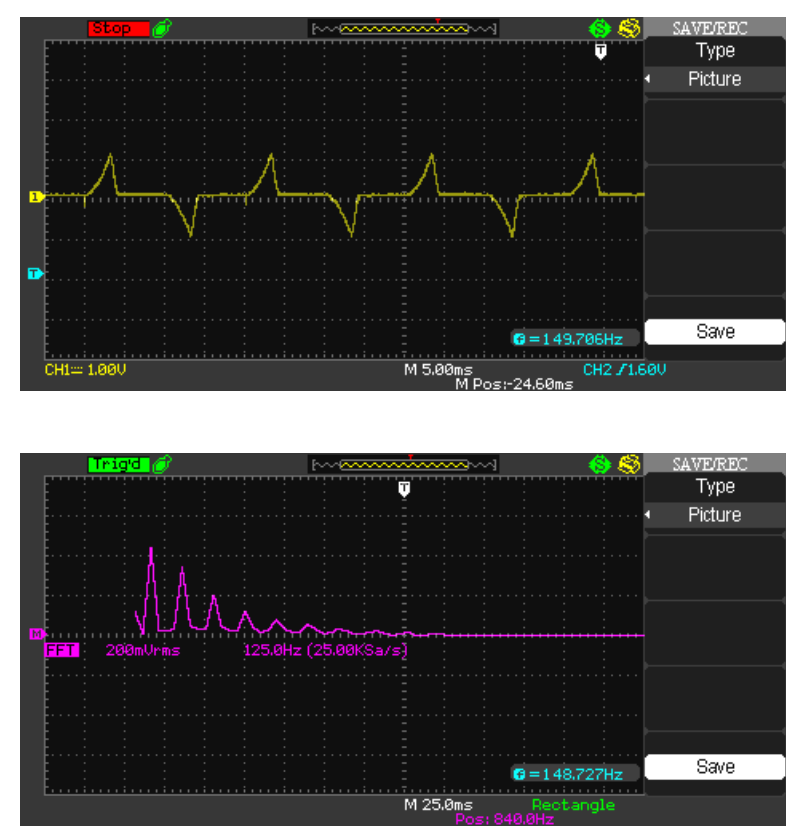

Fig. 30. Typical waveform of the extinction angle controlless than $90^{\circ}$ conduction (Voltage across one phase winding and FFT)

\section{Conclusion}

A comparative study of the phase angle control scheme and the extinction angle control scheme for the management of soft starting applicable to three phase Induction motors has been carried out. It has been established by way of MATLAB / SIMULINK simulation that the extinction angle scheme is better performing with regards to critical parameters like peak starting current, Power factor, THD, torque ripple etc. The experimental results clearly demonstrated the feasibility of such a computationally intensive extinction angle control scheme. There is wide scope for future research considering that only an open loop analysis has been done in this work. Closed loop soft starting by considering any of the real time parameters like current drawn, torque produced or speed obtained from time to time during starting can be carried out which will lead to immediate industrial applications.

\section{References}

[1] Rakesh Parekh, "AC induction Motor Fundamentals MICROCHIP AN887" Published by the MICROCHIP Technology Inc. 2003.

[2] J.Nevelsteen et. al., "Starting of large motors-methods and economics", IEEE Transaction on Industrial Applications, Vol. IA-25, pp. 1012-1018, 1989.

[3] Umar Farooq Siddiqui et. al., "Analysis Of Induction Motor By Soft Starters Using Power Switching Devices", International Journal of Advanced Electronics \& Communication Systems, Vol. 2, No. 3, 2013

[4] W. Shepherd, "Analysis of three phase induction motor with voltage control by thyristor switching", IEEE Transactions on Industry and General Applications, Vol. 4, No. 3, pp. 304-311,1968.

[5] A.M. Eltamaly et. al., "Performance evaluation of three-phase induction motor under different ac voltage control strategies' Part I', Electrical Machines and Power Electronics, pp. 770-774, 2007.

[6] Sachin S. Mestry, "Fault Tolerant Operations in Soft Starter for Induction Motors", Proceedings of Sixth IRAJ International Conference, October 2013.

[7] S. Charles et. al., "Power quality studies on a soft start for an induction Motor", International Journal of Recent Trends in Engineering, Vol. 1, 2009

[8] Ahmed Riyaz et. al., "Comparative performance analysis of Thyristor and IGBT based induction motor soft starters", International Journal of Engineering, Science and Technology, Vol. 1, No. 1, pp. 90105, 2009.

[9] A.R. Kashif et. al., "Soft starting of an induction motor using adaptive neuro fuzzy interface system", Proceedings of ICEE 07, pp. 1-5, April 2007.

[10] G. Zenginobuz et. al., "Performance Optimisation of Induction motors during voltage controlled soft starting", IEEE Trans. on Energy Conversion, Vol. 19, No. 2, pp. 278-288, June 2004.

[11] Fu Chao, "Design and Simulation of Three-phase AC Motor Soft-start", Intelligent System Design and Engineering Applications (ISDEA), pp: 554-557, 2013.

[12] Rashid M.H., "Power Electronics Circuits Devices 
and Applications", Second Edition, Prentice-Hall Inc, Englewood Cliff, New Jersey, 1993.

[13] Sun Zhiping, "Motor soft-start technology Review", Journal of Jilin Institute of Chemical Technology, pp. 56-60, 2013.

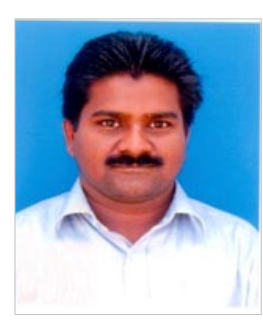

Mohamed Faizal He received the B.E. degree in Electrical and Electronics Engineering from Manonmaniam Sundaranar University, Tirunelveli, Tamil Nadu, India in 1998, the M.E degree in Power Systems Engineering from Anna University, Chennai, Tamil Nadu, India in 2004, where he is currently pursuing the Ph.D. degree. He is currently an Associate Professor and Head of Electrical and Electronics Engineering Department, National College of Engineering, Maruthakulam, Tirunelveli. He has more than 17 years of experience in teaching. His research interests are in Soft Computing Techniques and Electric Machine Protection \& Control.

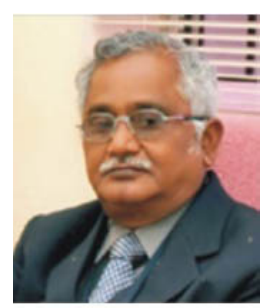

Subburaj He received the B.E. degree and the M.E. degree from Thiagarajar College of Engineering, Madurai / Madurai kamarajar University in 1977 and 1990, respectively. He received the $\mathrm{Ph} . \mathrm{D}$. degree from Anna University, Chennai in 2009. Presently he is working as Professor, Electrical and Electronics Engineering department of National Engineering College, Kovilpatti. He has more than 30 years of teaching experience in Engineering Institutions and 7 years in industry. He has published 30 papers in international conferences and 30 papers in reputed journals. He has produced six P.hd's and six are pursuing with him. He is an active member of IEEE, IE (I), and ISTE. His research interests are application of evolutionary computational methods in power system problems. 